\title{
Human Rights Activism Among North Korean Refugees in the UK: Hope for a Democratic Future?
}

\author{
Hyun-Joo $\operatorname{Lim}^{1}$ D
}

Accepted: 8 June 2021 / Published online: 13 July 2021

(c) The Author(s) 2021

\begin{abstract}
Social work plays a crucial role in defending the human rights of migrants, asylum seekers and refugees from systems of oppression. This paper explores the meanings and challenges of human rights activism and its driving forces among North Korean refugees in the UK. The data are drawn from life history interviews with 10 participants, together with two activists' public speeches. The findings suggest that gaining awareness of human rights after their escape had significant implications for the activists, giving meaning to their life and sparking on their activism. Simultaneously, they expressed misconceptions and criticisms from other fellow North Korean refugees as one of the greatest difficulties they encountered in their work. I argue that to overcome such challenges human rights activism requires altruism and a creative imagination that envisions better future lives for other North Korean people. Based on this, I propose altruistic political imagination (API) as a concept that captures North Korean activists' experiences, built on Passy's (2001) notion of political altruism, to put emphasis on the visionary aspect of their activism. I maintain that the concept of API potentially has a wider appeal to those activists who face similar situations to North Korean activists, as well as social work practitioners who work with forced migrants and/or marginalised communities.
\end{abstract}

Keywords Altruism · Altruistic political imagination $\cdot$ Human rights activism $\cdot$ Imagination $\cdot$ North Korean refugees

\section{Introduction}

This paper examines human rights activism among North Korean refugees living in the UK, using imagination as an analytical lens. Social work has the capacity to play a crucial role in defending the human rights of migrants, asylum seekers, and refugees from systems of oppression by supporting these communities with an empathic understanding of the socio-cultural, economic and political contexts in which their experiences are constructed (Drolet et al., 2017; Kallinikaki, 2019). Moreover, political activism and selfhelp as forms of social work can be highly instrumental in achieving justice for marginalised people (Mmatli, 2008; Social Workers Without Borders, 2017). In this respect, understanding the potential challenges and significance of activism among refugees is critical for social work practitioners. In particular, with a noticeable increase in the

Hyun-Joo Lim

hlim@bournemouth.ac.uk

1 Department of Social Sciences and Social Work, Bournemouth University, Bournemouth, UK number of North Korean refugees worldwide since the mid1990s, there is an urgent need for social workers to gain a better understanding of their lived experiences.

Approximately 1000 North Koreans have settled in the UK since 2004 (Office for National Statistics, 2015), the majority of whom reside in New Malden, the largest Korean community in Europe. Free NK (short for Free North Korea), a human rights organisation born out of this settlement, has been proactive in illuminating the reality of North Korea to Western society whilst also working towards subverting the regime by informing its fellow remainders about the outside world through the 'illicit' smuggling and distribution of newspapers. Whilst violations of human rights in North Korea are well-documented (e.g., KINU, 2016; UN Human Rights Council, 2014, 2019), human rights activism by its defectors is less well-known, despite its vital role. Thus, this paper seeks to illuminate this under-researched topic. It aims to (i) explore the subjective meanings that North Korean human rights activists attach to their activism, (ii) identify the challenges of their activism, (iii) develop a theoretical concept that captures the driving forces behind their activism and (iv) contribute to advancement in knowledge 
and understanding for social work practitioners in forced migrants' practices of activism, its obstacles and catalysts.

North Korea has developed a unique notion of human rights that prioritises collective rights over individual ones, different from the Western concept based on individual liberty. The officially known 'our style' of human rights created by Kim Jong Ill (late father of leader Kim Jong Un) comprises four principal tenets: (i) the right to national survival, (ii) dictatorship as the protection of human rights, (iii) granted by the fatherly leader and (iv) the use of dutybased language of human rights (Song, 2011, p. 150). These creeds clearly indicate the demands placed on citizens in the pursuit of the communal (national) goals through their absolute subordination to the Supreme Leader, disregarding their individual needs and desires. Reflecting on this, international bodies, such as the UN Human Rights Council, have identified numerous crimes against humanity in and outside the Democratic People's Republic of Korea (DPRK), including violations of the right to food and freedom of movement (UN Human Rights Council, 2014, 2019).

Such recognition has led to a range of attempts by international organisations to resolve the exigent matter, including the establishment of the UN Commission on Human Rights' mandate for the Special Rapporteur on Human Rights in North Korea since 2004, who reports the situation annually. Alongside this, numerous grassroots human rights organisations have sprung up in the UK, South Korea, and elsewhere, such as the aforementioned Free NK and North Korean Democracy Movement. These organisations have been involved in a variegated range of activities in raising awareness of human rights issues in the dictator state to the outside world, alongside sending leaflets and newspapers to people in the DPRK.

Among a very few studies focusing on North Korean human rights activism, Song (2017) analyses media discourse and interview data of five prominent North Korean defector activists based in the UK, the USA and South Korea. Song (2017) depicts those activists as 'examples of the survival of the fittest' (p. 296), whose prime purpose is 'to survive in new liberal capitalist environments' (p. 295).

However, my study suggests that the North Korean human rights activists do not place self-gain and their survival as a priority. Rather, they participate in activism to bring changes in North Korea for a better future for its people despite their clear awareness of the potential danger to themselves and their families. I propose that the role of this vision is vital in propelling these individuals in their activism. I argue that it is not only the collective imagination that drives North Korean defectors to their activism, but also altruistic imagination plays a critical role - their belief that they are doing something beneficial for the future of fellow North Korean people and their families. Founded on this, I propose the concept of 'altruistic political imagination' (API) as pertinent to the case of North Korean activists, built on Passy's (2001) notion of 'political altruism'.

\section{Theoretical Frameworks}

\section{Imagination}

Meaning-making and the quest for meaning constitute unique and central characteristics of human life (Frankl, 2006). As social beings, individuals' relations with other people are key in the construction of the subjective meanings that they attach to their behaviour: 'living in the world, we live with others and for others, orienting our lives to them' (Schutz, 1967 [original 1932], p. 9). As an existential concept, meaning is associated with the purpose of life, therefore directed towards the future (Lee, 2016). For Schutz (1967 [original 1932]) looking forward into the future is a central aspect of human action. In this respect, imagination plays a salient role in the lives of people.

The term imagination refers to the act or process of forming a mental picture of something not present (Oxford Dictionary, 2000). Drawing on this and scholarly writings presented below, imagination is defined as the act of creating a mental image that is future-oriented, which encapsulates an individual's cognitive ability to transform something absent or seemingly impossible at present into something possible in the future.

Imagination, Warnock (1994, p. 2) writes, "enables us to think about things that are absent, including things which no longer exist or do not yet exist. It is thus only through imagination that a man has a concept of himself as having a history which is not yet finished." Similarly, Illouz (2009, p. 398) suggests that symbols and images propel individuals into "a realm of possibilities entertained through the exercise of imagination". For Sartre (1948 [original 1940]), the act of imagination is like an incantation, which gives meanings to objects that do not have innate meanings. Imagination also presents 'an escape from worldly constraints' and an alternative version of the world (Sartre ibid., p. 155).

Imagination has become the quotidian feature of everyday lives of ordinary people in constructing their identity in the globalised contemporary society (Appadurai, 1996, 2000). For Appadurai (1996), the increased movement of people across different borders is a resultant outcome of people's imagination for better lives outside their national boundaries. Moreover, imagination continues to play a vital role in the minds of people in diaspora, creating meanings and identity through the juxtaposition between their past, present, and future life (Appadurai, 1996; Orgad, 2012).

Orgad (2012, p. 131) draws our attention to the ambivalent characteristics of imagination for refugees and their liminal status 'between past and future, here and there, old and new, 
nightmare and dream'. In this, Orgad challenges the dichotomous sequestration of previous life - a nightmare and new life - a dream that overlooks the complexity of migrants' experiences and the continual process of their lives.

Imagination impels subjects into collective action, built upon a 'community of sentiment' that binds people together through shared imaginations and feelings (Appardurai, 1996, p. 7-8). Collective imagination constructed on these selective memories plays a pivotal role in connecting the historical pathways of people's community (Borer, 2010). Therefore, it is key in shaping our approaches to the collective future in bringing changes to a world (Harrington, 1999).

Bloch (1995) provides a seminal framework for envisioning the future, 'the dreams of a better life.' Bloch (1995, p. 75) eloquently argues that hope is 'the most important expectant emotion, the most authentic emotion of longing'. For him, it is a fundamental constituent of human consciousness, which directs human action for the anticipatory future. For Bloch (1995), utopian aspirations are imperative in all freedom movements and thus imagination comprises an integral part of collective action. He distinguishes abstract utopia from concrete utopia - the former is wishful thinking but with no will to bring changes; the latter, denotes the achievable future that effects change. It is only a concrete utopia that embodies hope beyond the expression of desire in the realm of abstract utopia (Levitas, 1990).

\section{Altruistic Political Imagination}

In the act of imagination that is directed towards the better future of society, altruism forms a main facet. The term was created by Auguste Comte in 1851 (Scott \& Seglow, 2007), which referred to an act that is opposite to egoism (Twemlow, 2017). However, similar notions pre-existed in both Western and Eastern countries, such as ancient China (Dubs, 1951). According to Dubs (1951), the concept of ren (defined as 'benevolent love' for others) is a fundamental virtue of Confucianism. As an antithesis of egoism, the principal tenet of altruism is to foster the interests of others prior to those of selves (Scott \& Seglow, 2007). Thus, altruism is a critical constituent in collective life and 'the desirable future state of humanity' (Bykov, 2017, p. 798).

For Passy (2001), within the context of the solidarity movement altruism is constructed in the collective and political form through activists' participation in protecting other individuals' rights and interests. Based on the mobilisation of people for the same political goals from a collective perspective, Passy (2001, p. 6) defines political altruism as:

A form of behaviour based on acts performed by a group or/and on behalf of a group, and not aimed to meet individual interests; it is directed at a political goal of social change or the redefinition of power rela- tions; and individuals involved in this type of social change do not stand to benefit directly from the success deriving from the accomplishment of those goals.

Whilst the notion of political altruism represents human rights activism by North Korean refugees to a large extent, its exclusion of individual interests leaves a gap. The narratives of North Korean activists suggest that the goal of their activism is the achievement of a collective good through the transformation of North Korean society, yet their discourses around filial piety and duty to their families also form an important part of their motivation for activism. Additionally, their altruism has significant implications for themselves in constructing a meaningful life even if it is not their primary goal or interest. In this sense, altruism integrates individual as well as collective aspects. Together with this, their vision for the democratic future of the DPRK is a foundational force that drives them to activism. Without this imaginary vision, their political activism would be devoid of meaning. Thus, I maintain that the futuristic dimension needs to be articulated more explicitly than Passy's concept. Although the element of imagination and utopian vision are embedded in her ideas, given their significance, I propose 'altruistic political imagination' (API) as a more apt concept that encapsulates the human rights activism of North Korean activists. The central tenet of API is imagining a better future and life for others, specifically people remaining in the DPRK, including their families, as well as those who have escaped in search of better lives. I delineate API as:

Imagination that takes place in the sphere of politics and political movement for the interests of others in envisioning the better future state of a particular society or community. This act of dreaming better future lives for others becomes the thrust of individual and/or collective action that is directed towards achieving the imagined outcomes for the benefit of others.

To summarise, my concept differs from Passy's in three aspects: (a) it entails individual as well as group interests, (b) it treats the self as an essential part of altruism and (c) it regards the futuristic dimension as the main facet, and key to API is the visionary imagination that spurs on transformation in society to profoundly improve other people's lives.

\section{The Role of Social Work}

In improving the lives of refugees and supporting their resettlement processes, social work can play a vital role, based on its foundational principles of protecting and fostering human rights (United Nations, 1994). Drolet et al. (2017) suggest 
that it is important for social workers to understand sociocultural, economic and political contexts of sending and receiving societies through which the experiences of forced migrants are shaped. They further argue that working with these groups of people demands politicised social workers, who are committed to 'social justice, social action, inclusion and human rights' because structural racism, oppressive political practices and historical imperialism continue to affect their lives (Drolet et al., 2017, p. 631). In a similar vein, Mmatli (2008) proposes political activism as a strategy for social workers to bring positive changes in social policy and making real differences to the lives of those with whom they work. According to Mmatli, political education as part of activism can be a critical strategy to raise consciousness of the marginalised communities about structural inequalities and abusive systems that have caused their current plight and the possible alternatives to improve the situations. Consonant with this, Ife (2016) urges social work to critically engage with human rights discourse and reformulating them to be more progressive in the era dominated by neoliberalism and managerialism. He maintains that equating social workers as human rights workers has the potential to become more transformative in the lives of people who have been devalued in society to realise their rights and full humanity.

Protecting and fostering human rights undoubtedly constitute the core values of social work. However, the universal claims of human rights constructed by the West, founded on individualism, have been criticised for their hegemonic domination over non-Western countries and their limited applicability to these societies. For instance, in developing countries, more urgent concerns lie in broader issues around 'adequate income, education and health', rather than individual-focused rights (Skegg, 2005, p. 668). Moreover, Bauer and Bell (1999) question the suitability of such human rights in Asian countries where communitarian values are strongly espoused. Addressing this dispute, Skegg (2005) questions whether it is justifiable for Western countries to relinquish their obligations to act on human rights abuses in other countries in the name of respecting cultural diversity. Healy (2008) suggests that social work's dual commitment to cultural diversity and respect for individual rights may provide conciliatory solutions for these contentious issues around universalism and cultural relativism. Human rights work should be founded on universal 'ideas of a common humanity and globalised citizenship', and should take a contextualised approach towards intercultural practice (Skegg, 2005, p. 671).

Echoing this, Potocky and Naseh (2019) stress that social workers must base all of their work on a foundation of culturally competent practice, using their knowledge about the characteristics of the ethnic groups with whose members they work, their cultural stressors and strengths. They additionally suggest that using their cultural competence social workers can function as a bridge in segments of society, including conflict resolution, whilst also empowering those with whom they work by improving their ability to alter challenging situations. Building on these individual cases, social work practice can contribute to policy changes (Healy, 2008).

\section{Methodology}

This study took a phenomenological approach ((Schutz, 1967 [original 1932]); Weber, 1949) since it sought to investigate subjective meanings and how such meanings had affected human rights activism.

\section{Sampling}

Purposive sampling was used to ensure the sample met the inclusion criteria of being involved in North Korean human rights activism in the UK (Ritchie \& Lewis et al., 2003; Richie \& Spencer et al., 2003). Due to many defectors' general weariness and anxiety about revealing their identity, relying on someone who they knew and trusted was crucial in recruiting them, and thus, snowball sampling was identified as the most effective method of recruitment. Based on this, access to human rights activists began by establishing initial contact with the founder of Free NK. I introduced myself to him and expressed my interest in doing research on human rights activism via email. Following this, the first meeting was arranged, and he agreed to participate in my research whilst also helping me access other activists. Through his help, I made contact with other potential participants, who also introduced me to other activists.

All the participants were directly associated with Free NK, except one who worked collaboratively with its members rather than being an actual member, and who was a leading activist in another organisation based in Europe. The participants comprised six females and four males. Their age ranged from 30 to 70 s, but the majority were in their 40 s. In general, the activists were highly educated, with six out of ten having been educated at a degree level or equivalent.

\section{Data Collection}

Founded on the above methodological considerations, the life history interview was selected as a primary method in exploring the subjective and fuller life perspectives of the participants. This was combined with data collected at a public speaking event organised by the researcher at her institution. Two activists were invited to talk about their experiences in North Korea and their activism in the UK in June 2016. The event lasted 2 hours, and their speech 
was audio- recorded and transcribed verbatim. The extracts relating to human rights activism were taken out and analysed alongside the interview data. The interviews were conducted between 2016 and 2017. The interview began by outlining the key aims of the project and asking the participants to tell their life stories however they wanted, focusing on their life in North Korea, how and why they escaped the country and their human rights activism today. Whilst the interviewees talked, the researcher just listened, except for occasional nods (or 'yes') of acknowledgement. Once they finished this process, the interviewer (a native Korean speaker) asked probing questions. The interviews lasted between 2 and over 4 hours. All but one interview (9/10) were carried out in the Free NK office by the choice of the participants and one interview was conducted via Skype. All the interviews were tape-recorded, based on consent from the participants, and transcribed verbatim in Korean.

\section{Data Analysis}

The data were analysed using a thematic method (Ritchie \& Lewis et al., 2003; Richie \& Spencer et al., 2003). The first stage of the analysis began with familiarisation through reading and re-reading of the transcripts, during which all the data relevant to human rights activism were taken out from the whole interview data and put together in a separate word document. Following this, the researcher translated the Korean extracts into English. It made sense to carry out translation at this stage prior to systematic categorisation and indexing so the researcher could organise and analyse the data in English. Next, the data were arranged according to 'thematic sets' (Ritchie \& Lewis et al., 2003; Richie \& Spencer et al., 2003, p. 229) by putting them together. Interview extracts under these themes were reorganised into different hierarchies of main themes and subthemes: for instance, challenges of human rights activism as a main theme and inner enemy and finance as subthemes. The next step was to create a thematic chart, based on four key themes: meanings of human rights, the impact of human rights, challenges of human rights activism and altruism - reasons for activism. The researcher then applied a detailed reading of the extracts to find nuanced and subtle meanings conveyed in their narratives. Along with this, the researcher listened and relistened to the relevant sections of their audio recordings to note nuanced tones. The data analysis process continued linking to the theoretical frameworks dialectically. This allowed the development of a concept, altruistic political imagination, to represent the narratives of the activists more aptly. Concurrently, this process helped the refinement of the empirical data, having resulted in the reduction of the four themes to three by merging the first and the second together.

\section{Ethics}

Ethical issues were carefully considered and submitted to the researcher's university Research Ethics Committee for its review and approval (ID: 7382). Given the potentially high risk the research presented to the participants and their families remaining in the DPRK, all the necessary considerations were taken for the Committee's approval, including risk assessment. Ethical measures to minimise the potential risks were then carefully applied throughout the processes of the research from preparation, data collection, to the storage and use of the data. For instance, to protect their identity, anonymity and confidentiality, pseudonyms have been used in this paper. Also, some identifiable facts have been excluded from the analysis. Further, the participants were debriefed at the end of the interview and provided with contact details of local National Health Service (NHS) counselling and refugee services where they could receive free services if they needed or wished to.

\section{Findings}

The main findings from the data are presented under three main headings, starting with the subjective meanings and influence of human rights on activists. These have emerged as a vital starting point and building blocks of their activism. The second section examines the challenges of their activism, which are central in elucidating the main argument of this paper in the last section, the API. Despite challenges deriving from internal divisions among defectors and potential threats from the DPRK government, the wilful hope for the democratic future and better life for North Koreans has spurred on their activism.

\section{Meanings of Human Rights and Their Impact on Activists' Life}

The majority of the participants were unaware of the notion of human rights, let alone understanding the meaning of human rights, when they were in the DPRK. It was common that people began to hear about the term after they escaped to, for example, South Korea or the UK. This lack of understanding is also evident in the narrative of Mr. Lee who did not know how to articulate his experiences of human rights abuse by the regime in his interview with the UN Commissioners:

...I didn't know what human rights were, I had no clue so I just told them my life story and they said all 
of what I said were the violations of human rights. When I heard this, I realised we really lived in ignorance.

The investigation of Collins (2019) is congruous with the accounts of my interviewees, noting incognisance of the term human rights itself and the DPRK's official stance towards them among most North Koreans, due to the absence of teaching these in their education. However, unlike the views of defectors and ordinary North Koreans, there are officially established human rights in the DPRK, as noted previously.

The realisation and understanding of human rights as founded on individual and liberal ideas have had significant implications for activists' lives. It affects their involvement in the activism and provides meaning for their efforts. $\mathrm{Mr}$. Jin's narrative illustrates this: 'First of all, understanding human rights has given me the reason for my existence. Also, it has given me a sense of self-esteem that there is something that I can do for others.' As noted by Frankl (2006) and Schutz (1967 [original 1932]), meaning-making is significant in relation to others. Thus, the very process of gaining awareness of human rights has sparked some individuals' imaginations to act for the benefit of others. In the process of altruistic behaviour, 'tele-pathos - the sympathetic identification with another's suffering at a distance' (Sliwinski, 2009, p. 31) - functions as a significant medium for North Korean refugees to be able to connect with others and act for them: 'I think only those who can think of other people's pain as their own can participate in human rights activism' (Mr. Kang). Thus, in understanding North Korean human rights activists' involvement, this relational aspect is central as their act transcends the selfcentered concerns.

\section{The Inner Enemy}

Participants talked about numerous hurdles they encountered in their activism, including finance. Among these, the activists cited a lack of support and criticisms from other fellow North Korean people in Britain as the most challenging issue they face, as described by Mr. Jin: 'Personally one of the most difficult things is the prejudice of other defectors.' According to Mr. Jin, only about $7 \%$ of North Korean refugees in New Malden are involved in human rights activism. A sense of disappointment and regret originating from this small participation rate is reflected in the accounts of other interviewees:

Ms. Park: I wish more of our North Koreans here get involved in activism...Even a small voice, if gathered together, it becomes a loud voice, so I often think it would be good if they participate a bit more.
Moreover, according to the verdicts from my participants, it is evident that there is a misconception towards the motives of human rights activism among those who are not involved:

Ms. Keum: What is difficult is that many people say the reason why we are getting involved in human rights activism is because we seek fame. Also, many people say, "Why can't you live quietly when you come to a good country like this and why do you stir and bother even people left in North Korea not to live peacefully with your activism?" They say, "Because of you, we can't live peacefully" "So and so is a bad guy, we have said let's live peacefully but with this human rights activism, they have made North Korea know about us, monitor us so it has made our family's lives unliveable." Such criticism is the hardest thing that Free NK faces.

For those who criticise human rights activism, the activists are seen as disrupting the normative expectations of refugees who are obedient and docile subjects maintaining 'invisible' and 'quiet' lives (Nyers, 2006). Simultaneously, antagonism towards activists from other North Koreans also stems from seeing the activists as the 'troublemakers' who cause unnecessary threats for them and their families. Although these criticisms appear to be righteous on the surface, arguably it is evidence of the crtitics lack of imagination in envisioning an alternative form of society that challenges the existing social order of North Korea. In reality, the root cause of ordinary people's suffering and fear originates from 'total terror' (Tucker, 1965, p. 571) and the totalitarian regime's immoral treatment of its people, depriving them of their basic rights as humans. Thus, it can be argued that these people abide by the orthodox social imaginary of the regime even after their forced migration. Taylor (2004, p. 23) defines social imaginary as:

The ways in which people imagine their social existence, how they fit together with others, how things go on between them and their fellows, the expectations that are normally met, and the deeper normative notions and images that underlie these expectations.

Although Taylor's notion of social imaginary is created within the context of Western modernity, this could be applied to the experiences of North Korean refugees. In particular, the term imaginary is pivotal in legitimising the human rights abuses and the total control of the people in and outside the DPRK. It is these loosely joined normative values transmitted through stories and images alongside their memories that directly shaped their decision not to be part of human rights activism. It is this imaginary that continues to haunt the majority of people from North Korea, in combination with the tactics of fear and terror used by the DPRK government, as 
illustrated in the below narratives of Ms. So. Stories they were told about what had happened to people who challenged or disobeyed the government rules, the images emerging in the news, the memories of their past and learned helplessness originating from their past experiences - these form part of their social imaginary that operates as a controlling mechanism that limits their action for the future. Simultaneously, it is arguable that orthodox social imaginary inevitably represents a hegemonic ideology within a particular social milieu (Dey \& Mason, 2018). On the one hand, this guides people in their thinking and behaviour by imagining what the status quo looks like and what ideal behaviours fit into that 'imagined community' (Anderson, 1983). On the other hand, this concurrently puts constraint on people's capacity to imagine the alternative possible future and their subsequent action by constraining people's ability to dream of different versions of reality from the existing one that is dominantly built on the vested interests of elites and their malpractices (Dey \& Mason, 2018). In this context, human rights activism becomes the disruptive act that stirs up the established normative beliefs and expectations by challenging the legitimacy of the regime, its action and its treatment of people and presenting alternative possibilities, showing different kinds of social existence.

In the above narrative of Ms. Keum, the hint of fear of potential harm on their left-behind families is noticeable, which is noted by the participants as another factor that prevents people from getting involved in activism:

Ms. So: A difficulty is I have families in North Korea so I have very limited freedom and act in a restricted way. I can't reveal my face. I always fear revealing my voice or my identity a little bit itself. However, even if I am fearful, I am doing it bit by bit. Still very timid. I am most fearful about my family's safety...

According to Arendt (1951), terror forms an indivisible aspect of totalitarian governments. Arendt also argues that the mechanisms of indoctrination and violence are systematically used by totalitarian regimes not only to frighten people but also to sustain their ideological dogmas and lies. As suggested in the account of Ms. So, the ongoing terror and violence inflicted on people in North Korea has a far-reaching impact on their lives, beyond its national border.

The above accounts also remind us of the liminal state refugees' experience. As astutely expressed by Orgad (2012), there is no clear separation between their life before and after migration as their experiences and imaginary formed in North Korea having a persistent effect on their daily life.

\section{Reasons for Doing Human Rights Activism}

The above discussion on the challenges of their activism demonstrates that participating in North Korean human rights activism demands courage, vision and a will to bring positive changes to North Korean society. Participants describe the visionary images of North Korea principally in association with the protection of human rights:

Ms. Park: I wish North Korea becomes a country with a fair legal system. I wish it becomes a country with excellent human rights protection and everyone knows their human rights and fully exercise them.

It is notable from Ms. Park's account the emphasis she puts on is not only the protection of human rights but also people's knowledge of them. As noted previously, a lack of awareness of human rights in the DPRK is common among defectors, and for the activists, knowing marks a significant first step towards their action.

Together with these visions, a sense of doing something worthy for others is one of the major reasons why people participate in activism:

Ms. Keum: When I think of human rights, I foremost think of people in North Korea because it completely ignores them. So when I participate in human rights activism, I feel I have become a patriot, thinking that there is something I can do for the people because I am here outside North Korea. Even if I don't know it all, I get a comfort and I think it will become a comfort to those who are in North Korea, salving my meagre conscience.

In the narratives of the participants, such terms as conscience and duty in their relations with others emerge regularly. Markus and Kitayama (1991) suggest that East Asian countries, such as Korea and China, prioritise communal values over individual ones, owing to the influence of Confucianism alongside other socio-political factors. As discussed in the theory section, benevolent love for others - whether it is for families and relatives in the traditional Confucian sense or more universal love for all in the neoConfucian sense - is considered to be a fundamental virtue of Confucianism (Dubs, 1951). Given the establishment of the DPRK founded on the Communist ideology, intricately entwined with Confucianism (Clemens, 2016), it is unsurprising that activists' narratives are ridden with terms and phrases that reflect their sense of moral obligations to others.

Additionally, when the activists 'get a comfort' and 'feel proud' of their activism, this is more directed towards the future as they know their action will not bring immediate changes to North Korean people's lives. In this sense, their actions are guided by their imagination 
or dreams of the better future for other people. This altruistic behaviour also comes from their awareness and emphatic understanding of other people's suffering as well as their own (Sliwinski, 2009). In a similar vein, some of their decision to get involved in human rights activism originates from their realisation that short-term support, such as remittance, would not fundamentally alter ordinary North Korean people's lives as long as the totalitarian regime continues to rule the country:

Mr. Jin: One of the problems is my parents and siblings are still in North Korea. If I think of what would be the least duty that I can fulfil from an Oriental cultural perspective, sending money every month, of course it will help with their food, clothes, and shelter but it can't change their life completely. So if I intend to bring complete freedom, equality and happiness to my parents... then changing North Korean society, enabling democracy to seep into North Korea, so making people enjoy genuine freedom and human rights; that is the best present I can give to them, so that's why I'm doing this activism.

This account indicates Mr. Jin's strong sense of love, filial piety, and duty towards his family, reflecting the continuing influence of Confucianism, alongside his desire to transform the DPRK for the benefit of others. Although his participation in the activism might put his family in danger and thus appears to avert the notion of altruism, achieving the transformation of the DPRK unavoidably demands a certain degree of compromise and sacrifice due to the regime's terrorising treatment of people to retain its current power. The participants are acutely aware of this dilemma, as illustrated by Mr. Lee's account:

If I get involved in human rights activism and shout out, the North Korean government might threaten or kill my family. However, ultimately the whole North Korean citizens are my brothers and family so all the activists think that their families could be sacrificed. If you don't have that mentality, if you just think of your family, you can't do anything...My current activism might become the target of oppression for my family in North Korea from the government, but someone has to act.

Given the gravity of the situation, there is an acceptance among activists that a short-term compromise is inevitable for a bigger and longer-term cause, as can be inferred from this excerpt. Similarly, Scott and Seglow (2007) point out that sacrifice is an inevitable component of altruism. Consonant with this, it is clear from Mr. Lee's account that being able to get involved in the activism demands a vision beyond the immediate concerns of their family's safety even if his desire to protect his family's lives is unequivocally clear in his previous narrative. Thus, their activism would only be possible with the concrete utopian dream of the future.

\section{Discussion and Conclusion}

This paper contributes to social workers' understanding of the characteristics of North Korean refugees and communities, together with the challenges they encounter. The findings suggest that most activists were not aware of the notion of human rights, even the terms, until they fled the DPRK to other countries. Having gained the understanding of the notion has been crucial for the activists in terms of finding meaning in their life and for their activism. In association with this, the role of politicised social work professionals can be significant in the lives of North Korean activists through their commitment to human rights and social justice (Drolet et al., 2017; Ife, 2016). Consistent with this, the use of a human rights framework by social workers can help this group of people by further strengthening their awareness of rights and its fundamental values (Skegg, 2005). This can be especially empowering for North Korean activists by reaffirming the values and salience of human rights not only for their personal life but also for their activism in the terrain imbued with misunderstanding, tensions and conflicts.

Freeman (2017) proclaims that the principal credo of the Western notion of human rights is to protect individuals or groups from abuse of power. However, the Western concept of human rights has been criticised by scholars for its hegemonic position and its limited applicability in non-Western cultures, which highly value communitarianism over individualism (Bauer \& Bell, 1999; Skegg, 2005). As stated in the 'Introduction', the dominant cultural and political ideology of North Korea is collectivism and its official human rights principles are built on this. This raises a question over the relevance of the Western notion of human rights in the DPRK. Whilst there is an undeniable chasm between the West and the DPRK, fundamental rights, such as food security and freedom of expression, are essential rights that affect all humanity, regardless of their cultural heterogeneity. For instance, as illuminated in the UNHRC Reports $(2014,2019)$, the violations of such rights have had devastating impacts on North Koreans beyond geographical boundaries. This has raised an urgent need for further action at local, national and international levels. In this regard, focus on dichotomy seems ineffective and less relevant in addressing the dire human rights abuse against North Koreans. Hence, social work professionals need to move beyond the dichotomy in working with such human rights activists, focusing on universal common humanity and global citizenship (Skegg, 2005) whilst also finding conciliatory solutions (Healy, 2008). This also means encouraging these activists 
to start thinking about human rights principles that fit into the socio-cultural and economic conditions of North Korea, rather than uncritically following the dominant model. In this, raising consciousness through political education can be instrumental in supporting these individuals and communities (Mmalti, 2008).

One of the most pressing issues that activists have to deal with is internal division. The lack of cohesion within the North Korean community and misconceptions towards activists presents setbacks in their activism. I argue that the social imaginary (Taylor, 2004) held by the majority of North Korean refugees - the socially expected docile bodies of North Korean people who accept the totalitarian dictatorship and its rampant human rights abuse as the norm - puts a constraint on the visionary activism in the UK by adhering to their invisible and voiceless status. Whilst their escape from the DPRK and quest for new lives in different countries through multiple border crossings have an element of challenging the regime, I maintain that many DPRK refugees' lack of political participation and resentment towards human rights activists demonstrate little change. In that sense, North Korean human rights activism becomes a challenge against this fixated, limited social imaginary. In these thorny situations, social workers have the potential to play a positive role in conflict resolution and improving the internal cohesion of such communities by raising awareness of members' basic rights and entitlement as human beings and educating them about the effects of oppressive systems in their exit and host societies (Mmalti, 2008; Potocky \& Naseh, 2019). This requires social work professionals' clear understanding of socio-cultural, economic and political situations of both milieux, together with cultural power structures and the capital these communities bring (Drolet et al., 2017). Raising consciousness could enable these members to work together to effect changes in existing social institutions and their practices (Mmalti, 2008; Potocky \& Naseh, 2019). This also potentially implies the need to challenge existing social policies that are oppressive and discriminatory towards migrants and refugees. These findings undoubtedly suggest that getting involved in North Korean human rights activism requires courage and vision beyond an abstract dream, as well as a concrete hope and imagination that entails the will to bring profound changes to a society and its people. Reflecting on this, I have developed the concept of altruistic political imagination (API) to represent the motivating force for North Korean human rights activism. As noted in my theoretical frameworks' section, with API, the emphasis lies in the future-directed, visionary imagination that is entwined with altruistic concerns and goals within the realm of politics and political activism. I argue that, without such a vision and determination, maintaining human rights activism would be almost impossible because of the immense challenges presented to the activists. It is only possible because of their understanding of the inevitability of seeing beyond their immediate support and concerns for their families, the imaginary of an alternative society and the broader benefits it will generate for the future generations. In this sense, their activism is significant for the future of North Korea and its people. Also, the concept of API potentially has a wider appeal to those activists who face similar situations to North Korean activists. This could include social work practitioners who work with forced migrants and/or marginalised communities. If they incorporate political activism into their practice, the futuristic vision could be instrumental in achieving such goals.

The paper has a few limitations. Primarily, it focuses on the experiences of activists based in the UK. It would have been illuminating to compare and contrast their narratives with those living in other countries, such as South Korea and the USA. Given social work's vital role in liberating people from systems of oppression and empowering them, future research should involve collaborative projects with (North Korean) refugee communities in building harmonious and stronger communities that realise their human rights. Moreover, social workers may form advocacy groups in collaboration with such communities and their leaders to protect and promote their human rights whilst challenging unjust policies on migrants and refugees.

Acknowledgements I would like to thank Prof Edwin van Teijlingen, Prof Jonathan Parker and Prof Sara Ashencaen Crabtree at Bournemouth University for their valuable comments on the drafts of the paper. I would also like to thank two anonymous reviewers of this article for their helpful comments. Finally, I would like to thank Rob Casey for his help throughout the process of writing the article.

Funding Financial support was received from Bournemouth University.

\section{Declarations}

Ethics Approval This study was performed in line with the principles of the Declaration of Helsinki. Approval was granted by the Ethics Committee of Bournemouth University (Date: 16/10/2015, No: 7382).

Consent to Participate Written informed consent was obtained from all individual participants included in the study.

Consent for Publication Written informed consent for publication was obtained from all individual participants in the study.

Conflict of Interest The author has no conflicts of interest to declare that are relevant to the content of this article.

Open Access This article is licensed under a Creative Commons Attribution 4.0 International License, which permits use, sharing, adaptation, distribution and reproduction in any medium or format, as long as you give appropriate credit to the original author(s) and the source, provide a link to the Creative Commons licence, and indicate if changes were made. The images or other third party material in this article are included in the article's Creative Commons licence, unless indicated 
otherwise in a credit line to the material. If material is not included in the article's Creative Commons licence and your intended use is not permitted by statutory regulation or exceeds the permitted use, you will need to obtain permission directly from the copyright holder. To view a copy of this licence, visit http://creativecommons.org/licenses/by/4.0/.

\section{References}

Anderson, B. (1983). Imagined communities. Verso.

Appadurai, A. (1996). Modernity at large: Cultural dimensions of globalization. The University of Minnesota Press.

Appadurai, A. (2000). Grassroots globalization and the research imagination. Public Culture, 12(1), 1-19.

Arendt, H. (1951). The origins of totalitarianism. Penguin Books.

Bauer, J., \& Bell, D. (Eds.). (1999). The East Asian challenge for human rights. Cambridge University Press.

Bloch, E. (1995). The principle of hope. Translated by N. Plaice, S. Plaice and P. Knight. Cambridge, Massachusetts: The MIT Press.

Borer, M. I. (2010). From collective memory to collective imagination: Time, place, and urban redevelopment. Symbolic Interaction, $33(1), 96-114$.

Bykov, A. (2017). Altruism: New perspectives of research on a classical theme in sociology of morality. Current Sociology Review, 65(6), 797-813.

Clemens, W. C., Jr. (2016). North Korea and the world: Human rights, arms control, and strategies for negotiation. The University Press of Kentucky.

Collins, R. (2019). North Korea's organisation and guidance department: The control tower of human rights denial. Committee for Human Rights in North Korea. https://www.hrnk.org/uploads/ pdfs/Collins_OGD_Web.pdf

Dey, P., \& Mason, C. (2018). Overcoming constraints of collective imagination: An inquiry into activist entrepreneuring, disruptive truth-telling and the creation of 'Possible Worlds.' Journal of Business Venturing, 33, 84-99.

Dictionary, O. (2000). Oxford advanced learner's dictionary of current English (6th ed.). Oxford University Press.

Drolet, J., Enns, R., Kreitzer, L., Shankar, J., \& McLaughlin, A.-M. (2017). Supporting the resettlement of a Syrian family in Canada: The social work resettlement practice experience of social justice matters. International Social Work, 61(5), 627-633.

Dubs, H. H. (1951). The development of altruism in Confucianism. Philosophy of East and West, 1(1), 48-55.

Frankl, V. (2006). Man's search for meaning. Beacon Press.

Freeman, M. (2017). Human rights (3rd ed). Polity Press.

Harrington, W. M. (1999). Our collective future: A triumph of imagination. Quest, 51, 272-284.

Healy, L. M. (2008). Exploring the history of social work as a human rights profession. International Social Work, 51(6), 735-748.

Ife, J. (2016). Human rights and social work: Beyond conservative law. Journal of Human Rights and Social Work, 1(1), 3-8.

Illouz, E. (2009). Emotions, imagination and consumption. Journal of Consumer Culture, 9(3), 377-413.

Kallinikaki, T. (2019). Social work education in uncertain times: Protecting the human rights of migrants. Journal of Human Rights and Social Work, 4, 28-35.

Korea Institute for National Unification (KINU). (2016). White paper on human rights in North Korea. https://www.hrnk.org/uploads/ pdfs/265556.pdf

Lee, G. L. (2016). The quest for meaning in life in six patients living with advanced cancer: A qualitative longitudinal study. International Journal of Existential Psychology \& Psychotherapy, 7(20). https://www. meaning.ca/ijepp-article/vol7-no2/the-quest-for-meaning-in-life-in-sixpatients-living-with-advanced-cancer-a-qualitative-longitudinal-study/
Levitas, R. (1990). Educated hope: Ernst Bloch on abstract and concrete utopia. Utopian Studies, 1(2), 13-26.

Markus, H. R., \& Kitayama, S. (1991). Autonomy and relatedness in cultural context: Implications for cognition, emotion and motivation. Psychological Review, 98, 224-253.

Mmatli, T. (2008). Political activism as a social work strategy in Africa. International Social Work, 51(3), 297-310.

Nyers, P. (2006). Rethinking refugees: Beyond state of emergency. Routledge.

Office for National Statistics. (2015). Population by country of birth and nationality. Office for National Statistics.

Orgad, S. (2012). Media representation and the global imagination. Polity Press.

Passy, F. (2001). Political altruism and the solidarity movement: An introduction. In M. Giugni \& F. Passy (Eds.), Political altruism? Solidarity movements in international perspectives (pp. 3-25). Rowman \& Littlefield Publishers.

Potocky, M., \& Naseh, M. (2019). Best practices for social work with refugees and immigrants (2nd ed.). Columbia University Press.

Ritchie, J., Lewis, J., \& Ellam, G. (2003). Designing and selecting samples. In J. Ritchie \& J. Lewis (Eds.), Qualitative research practice (pp. 77-108). Sage Publications Ltd.

Ritchie, J., Spencer, L., \& O’Connor, W. (2003). Carrying out qualitative research. In J. Ritchie \& J. Lewis (Eds.), Qualitative research practice (pp. 219-262). Sage Publications Ltd.

Sartre, J-P. (1948 [original 1940]). The psychology of the imagination. Routledge.

Schutz, A. (1967 [original 1932]). The phenomenology of the social world. Translated by G. Walsh \& F. Lehnnert. Northwestern University Press.

Scott, N., \& Seglow, J. (2007). Altruism. McGraw-Hill Education.

Skegg, A.-M. (2005). Human rights and social work: A western imposition or empowerment to the people? International Social Work, 48(5), 667-672.

Sliwinski, S. (2009). The aesthetics of human rights. Culture, Theory and Critique, 50(1), 23-39.

Social Workers Without Borders. (2017). What we do. https://www. socialworkerswithoutborders.org/what-we-do

Song, J. (2011). Human rights discourse in North Korea: Post-colonial, Marxist and Confucian perspectives. Routledge.

Song, J. (2017). Co-evolution of networks and discourses: A case from North Korean defector-activists. Australian Journal of International Affairs, 71(3), 284-299.

Taylor, C. (2004). Modern social imaginaries. Duke University Press.

Tucker, R. C. (1965). The dictator and totalitarianism. World Politics, 17(4), 555-583.

Twemlow, S. (2017). Prologue: Evolution part II: The understated significance of altruism and cooperation. Psychoanalytic Inquiry, $37(7), 433-435$.

United Nations. (1994). Human rights and social work: A manual for schools of social work and the social work profession. Professional Training Series No. 1. Geneva: UN Centre for Human Rights.

UN Human Rights Council. (2014). Report of the commission of inquiry on human rights in the Democratic People's Republic of Korea. UN General Assembly. https://documents-dds-ny.un.org/doc/UNDOC/ GEN/G14/108/71/PDF/G1410871.pdf?OpenElement

UN Human Rights Council. (2019). Report of the special rapporteur on the situation of human rights in the Democratic People's Republic of Korea, UN General Assembly. https://reliefweb.int/report/ democratic-peoples-republic-korea/report-special-rapporteursituation-human-rights-3

Warnock, M. (1994). Imagination and time. Blackwell Publishers.

Weber, M. (1949). The methodology of the social sciences. The Free Press.

Publisher's Note Springer Nature remains neutral with regard to jurisdictional claims in published maps and institutional affiliations. 